Document downloaded from:

http://hdl.handle.net/10251/157589

This paper must be cited as:

Infante, D.; Llavori, I.; Zabala, A.; Giner Maravilla, E. (2019). The minimum shear stress range criterion and its application to crack orientation prediction in incomplete contact fretting problems. International Journal of Fatigue. 129:1-9.

https://doi.org/10.1016/j.ijfatigue.2019.105223

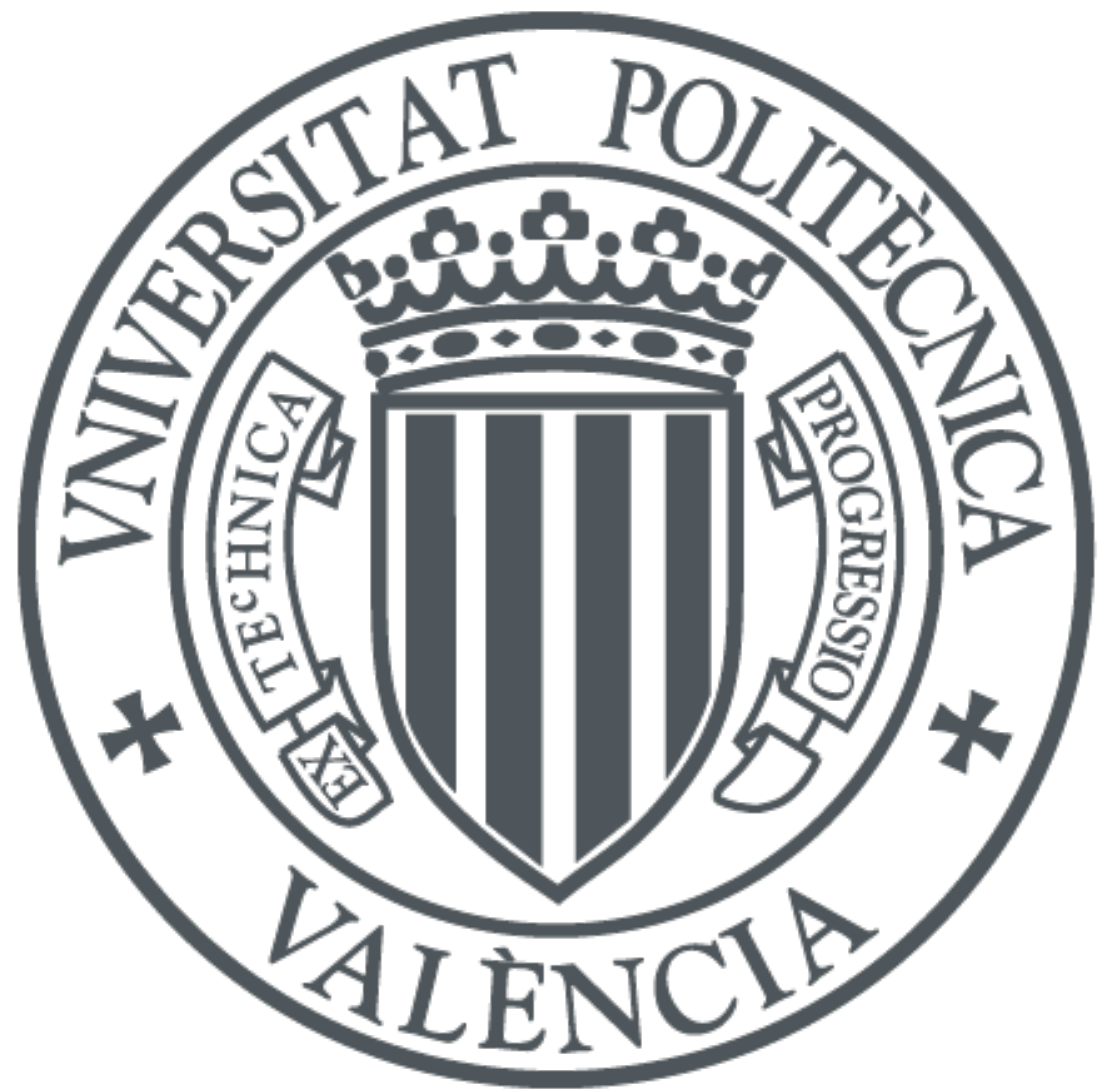

The final publication is available at

https://doi.org/10.1016/j.jifatigue.2019.105223

Copyright Elsevier

Additional Information 


\title{
The minimum shear stress range criterion and its application to crack orientation prediction in incomplete contact fretting problems
}

\author{
Diego Infante-García ${ }^{\mathrm{a}, *}$, Iñigo Llavori ${ }^{\mathrm{b}}$, Alaitz Zabala ${ }^{\mathrm{b}}$, Eugenio Giner ${ }^{\mathrm{c}}$ \\ ${ }^{a}$ Dept. of Mechanical Engineering, University Carlos III of Madrid, Avda. de la \\ Universidad 30, 28911 Leganés, Madrid, Spain. \\ ${ }^{b}$ Surface Technologies, Mondragon University, Loramendi 4, 20500 \\ Arrasate-Mondragón, Spain. \\ ${ }^{c}$ Centre of Research in Mechanical Engineering - CIIM, Dept. of Mechanical \\ Engineering and Materials, Universitat Politècnica de València, Camino de Vera, \\ 46022 Valencia, Spain.
}

\begin{abstract}
A proper prediction of crack paths is required when assessing accurately the fatigue crack propagation life. Recently, some authors have pointed out that the criterion of minimum shear stress range leads to inconsistent results when predicting fretting crack paths under incomplete contacts. In this paper, different fretting experiments with cylinder-to-flat contact found in the literature are reviewed, and the corresponding crack path prediction using the extended finite element method and the minimum shear stress range crack orientation criterion is performed. Results show the applicability of the criterion to predict the crack orientation during stage II in incomplete contact fretting problems.

Keywords: Crack paths; fretting fatigue; incomplete contact; minimum shear stress range.
\end{abstract}

\footnotetext{
${ }^{*}$ Corresponding author. Tel.: +34-610243653 .

Email address: dinfante@ing.uc3m.es (Diego Infante-García)
} 


\section{Introduction}

Cracks, defects or voids are present in many engineering components either due to manufacturing or due to severe service conditions. Furthermore, a relevant portion of the total fatigue life of a component is consumed in the growth of small fatigue cracks until complete fracture under certain loading conditions. It is for this reason that the study of crack propagation has become essential in damage tolerance design approaches and failure analyses. Two fundamental aspects of the crack propagation stage are the crack path and the crack growth rate $[1,2]$. In addition, components are usually subjected to multiaxial cyclic loading, giving rise to crack multi-mode loading, as it is the case in fretting fatigue cracks. A crack subjected to mixed mode loading (I+II) may propagate either co-planar or deviate at a certain angle to its original direction, following the maximum tensile or shear stress plane (mode I or mode II controlled), respectively [3]. Several criteria can be found in the literature for mode I controlled crack growth, as the Maximum Tangential Stress (MTS) criterion [4], the maximum strain energy density criterion [5] and the maximum energy release rate [6]. Many authors have demonstrated that the angles predicted by the aforementioned criteria are very similar [7] under proportional loading conditions. Because principal stress directions in a component are kept constant during a loading cycle under monotonic or proportional loading, the orientation of the maximum tensile stress plane is also kept constant. Thus, the crack direction can be easily assessed. In contrast, the orientation of the maximum tensile stress plane changes during a loading cycle under non-proportional loading, such as in fretting fatigue problems. Therefore, the orientation criteria proposed for proportional loading usually lead to inconsistent results 
$[8,9]$. Based on the stress intensity factors $k_{\mathrm{I}}^{*}(\theta)$ and $k_{\mathrm{II}}^{*}(\theta)$ associated with an infinitesimally small virtual crack emanating from the original branched crack [10], Hourlier et al. [11] considered three directions where a crack can propagate: in the direction of maximum range of $k_{\mathrm{I}}^{*}\left(\max \left(\Delta k_{\mathrm{I}}^{*}\right)\right)$, the direction of absolute maximum $k_{\mathrm{I}}^{*}$ or in the direction of maximum crack growth rate calculated from pure mode I tests $\mathrm{d} a / \mathrm{d} N=f\left(K_{\mathrm{I}}^{\max }, \Delta K_{\mathrm{I}}\right)$. The orientation criteria of maximum crack growth was in good agreement with the experimental crack paths in a material with a relevant mean stress effect on crack growth rate (AU4G aluminium). However, the criterion of $\max \left(\Delta k_{\mathrm{I}}^{*}\right)$ predicted better results in a 35NCD16 steel. Other authors have pointed out that, under non-proportional conditions, a crack follows a trajectory minimizing $\Delta K_{\mathrm{II}}[12-16]$. For example, Kitagawa et al. [12] and Qian et al. [15] found that $\Delta K_{\text {II }}$ was almost zero along the crack paths in cruciform specimens under biaxial out-of-phase loading.

In fretting fatigue problems, the crack remains closed during a relevant part of a loading cycle even for positive stress ratios at the early stages of the crack growth [17], giving rise to friction between crack faces. Therefore, the applicability of the aforementioned criteria is a challenging task due to the calculation of the stress intensity factors (SIFs) when the crack remains closed. The reason is because the use of domain independent integrals, such as the interaction integral, needs the consideration of crack face tractions through line integrals along crack faces up to the crack tip. Those stresses are difficult to compute accurately in a FE analysis (see e.g. [18] and references therein). In this way, stress based criteria for crack propagation, which do not require SIFs calculation, have become an efficient tool in fretting fatigue problems due to the simplicity of their application and 
the accuracy of their predictions. Dubourg and Lamacq [19] proposed a criterion based on the direction where the effective range of the circumferential stress is maximum $\left(\max \left(\Delta \sigma_{\mathrm{n}, \mathrm{eff}}\right)\right)$ along a loading cycle. The criterion was successfully applied to fretting fatigue problems under incomplete contact configurations, showing a good agreement with the experimental crack paths. On the other hand, an extension of the criterion of local symmetry for non-proportional loading was proposed by Giner et al. [16], where the predicted crack orientation is the direction in which the shear stress range at the crack tip is minimized, $\min (\Delta \tau)$. The criterion of $\min (\Delta \tau)$ was validated for complete contact fretting fatigue problems.

Recent works in the literature have questioned the applicability of the $\min (\Delta \tau)$ criterion to cylindrical-to-flat contact. Cardoso et al. stated in [20] that "The criteria based on stress field, $\min (\Delta \tau)$, led to inconsistent predictions" and Pereira and Wahab commented on the same issue in [17] "the use of their methodology in cylindrical pad configuration may lead to wrong predictions". In this paper, we show that the $\min (\Delta \tau)$ criterion leads to good predictions in fretting problems under incomplete contact configurations. Three experimental fretting problems with different loading conditions have been analysed using linear elastic fracture mechanics (LEFM), the extended finite element method (X-FEM) and the $\min (\Delta \tau)$ criterion. The experimental crack paths reported by Baietto et al. [21], Hojjati-Talemi et al. [22] and Proudhon et al. [23], which report the experiments used as reference in [17] and [20], are compared to the crack paths predicted by the $\min (\Delta \tau)$ criterion in this work, showing a good correlation. In addition and for the sake of clarity, we give some indications regarding the implementation of the criterion and its application to a numerical problem with 
a known solution of reference.

\section{The minimum shear stress range criterion}

The minimum shear stress range criterion states that a crack will grow in the direction in which the shear stress range $\Delta \tau$ at the crack tip is minimized [16]. In the plane of minimum shear stress range, less energy is dissipated in terms of friction when crack faces contact each other. Therefore, the crack has more energy available to grow. Since shear stresses develop always in two orthogonal planes, the prospective growth plane is the plane for which the maximum normal stress range $\Delta \sigma_{\mathrm{n}}$ is achieved, due to the fact that less friction energy is lost. This criterion can be considered as an extension for non-proportional loading conditions of the "criterion of local symmetry" proposed by Cotterell and Rice [24], which states that a crack follows a path for which $K_{\mathrm{II}}=0$. Under non-proportional loading, this condition can be extended to the path where the range of $\Delta K_{\mathrm{II}}$ is minimum. In this way, the criterion is analogous to the criterion of $\min \left(\Delta k_{\mathrm{II}}^{*}\right)$, based on the virtual stress intesity factors, for which a crack follows a trajectory minimizing $\Delta K_{\mathrm{II}}$. In addition, the $\min (\Delta \tau)$ criterion is in line with the principle that a crack will grow in the direction which maximizes the strain energy release rate [10]. The advantage of using $\min (\Delta \tau)$ criterion instead of $\min \left(\Delta k_{\mathrm{II}}^{*}\right)$ criterion is that it is not necessary to compute $K_{\mathrm{II}}$, which can be cumbersome under crack face contact conditions, as explained above. $K_{\mathrm{II}}$ is needed to estimate $k_{\mathrm{II}}^{*}$ as detailed e.g. in [13] and [25].

Different approaches can be followed in order to search for the prospective angle or angles where the condition of $\min (\Delta \tau)$ occurs. If the linearelastic stress field is computed through numerical methods such as the finite 


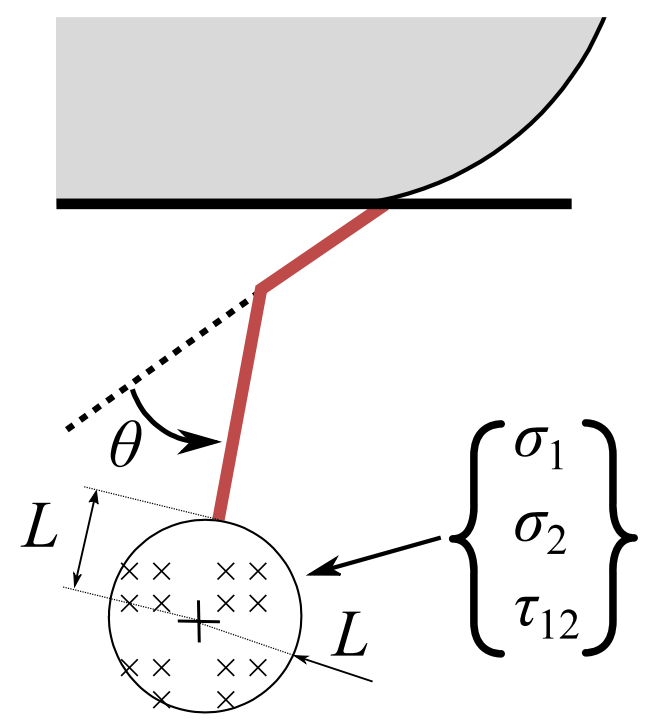

Figure 1: Sketch of the application of the $\min (\Delta \tau)$ criterion and sign convention for crack propagation angles.

element method (FEM) or the extended finite element method (X-FEM), the stress field is calculated discretely at the integration points (IPs). In this work, the proposed approach consists in obtaining the average value of the linear-elastic stress field at the IPs located within a circle of radius $L$ and whose centre is positioned along a line extended from the crack tip at a distance $L$ as shown in Fig. 1. The average stress field is calculated at discrete time increments along a loading a cycle. Next, $\Delta \tau(\theta)$ and $\Delta \sigma_{\mathrm{n}}(\theta)$ are evaluated for a range of $\theta \in\left[\frac{-\pi}{2}, \frac{\pi}{2}\right]$ in order to obtain the angles where $\Delta \tau$ is minimum. This approach can be easily implemented and leads to good results, as verified in the next section. 


\subsection{Application of the min $(\Delta \tau)$ criterion to the Westergaard's problem}

The Westergaard's problem is used here as a benchmark problem with known solution of reference to show that the numerical implementation of the criterion is valid, in comparison to the criterion of $\min \left(\Delta k_{\mathrm{II}}^{*}\right)$. The Westergaard's problem, whose domain is infinite, can be accurately modelled using a finite domain through the boundary conditions formulated by Giner et al. in [26]. An infinite plate with a crack of size $2 a$ is subjected to uniform remote tangential and normal tractions. The exact solution of the $\operatorname{SIFs}\left(K_{\mathrm{I}}^{\mathrm{ex}}\right.$ and $\left.K_{\mathrm{II}}^{\mathrm{ex}}\right)$ of the numerical model is set through the boundary conditions applied to the model of size $2 b$ and $2 c$ (further details can be found in [26]). Moreover, the problem can be reduced to half domain due to antisymmetry. Therefore, half of the crack is modelled using an in-house implementation of X-FEM in Abaqus [27]. In this problem, consistent units (c.u.) are employed and related to the crack size $2 a$. The parameters $2 a$, $b$ and $c / 2$ are set to 1 length units. The element size employed is $a / 16$. A sketch of the problem and the mesh of the numerical model is shown in Fig. 2.

Two different loading cycles are analysed. Case 1: steady $K_{\mathrm{II}}$ and variable $K_{\mathrm{I}}$ with stress ratio 0.1 and triangular waveform. Case 2: variable $K_{\mathrm{I}}$ with a stress ratio of 0.1 and $K_{\mathrm{II}}$ with stress ratio of -1 and $180^{\circ}$ phase difference, both as triangular waveforms. These loading cycles are usually found in cracks under fretting fatigue [17]. Fig. 3 shows the loading cycle and the range of $k_{\mathrm{II}}^{*}$ during a loading cycle and $k_{\mathrm{II}}^{*}$ at different loading time instants $(t)$ as a function of $\theta$ using the equations proposed in [10]. As can be seen in Fig. 3, the $\min \left(\Delta k_{\mathrm{II}}^{*}\right)$ is achieved at $\theta=0^{\circ}$ for case 1 and at $\theta=23^{\circ}$ for case 2. Note that there is not any numerical solution given in Fig. 3. 

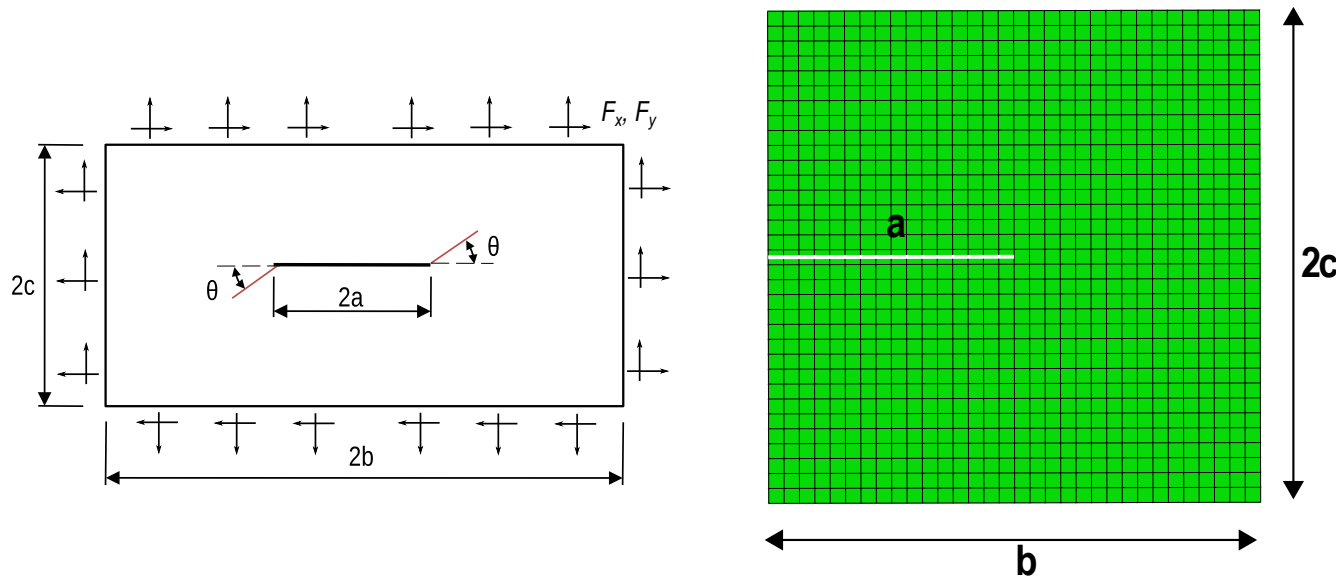

Figure 2: Sketch of the numerical model of Westergaard's problem (small arrows represent applied nodal forces $F_{x}$ and $F_{y}$ ) and definition of the prospective angle (left) and mesh of the numerical model (right).

Fig. 4 summarizes the results obtained of the methodology proposed above to obtain the prospective angle with $\min (\Delta \tau)$. The coordinate transformation is performed on the averaged stresses of the GPs ahead of the crack tip, being the size of $L$ equal to the element size (a/16). Fig. 4 a) and c) plot $\sigma_{\mathrm{n}}(\theta)$ during a loading cycle for case 1 and 2, respectively. In addition, subfigures b) and d) plot $\tau(\theta)$ during a loading cycle for both cases $([*]$ Note that the curves $\Delta \tau$ in subfigures b) and d) are the same as in subfigures a) and c), respectively). As can be seen in subfigure a), $\min (\Delta \tau)$ is achieved at $\theta=0^{\circ}$ for case 1 . In case 2 , it can be observed in subfigure c) that $\min (\Delta \tau)$ is reached at two angles: $\theta=24^{\circ}$ and $-66^{\circ}$. In this case, as stated by the criterion, the chosen angle is the angle with highest $\Delta \sigma_{\mathrm{n}}$. As expected, these results show that the criterion $\min (\Delta \tau)$ predicts angles very similar to the predicted by the $\min \left(\Delta k_{\mathrm{II}}^{*}\right)$ criterion. The differences found are mainly caused by the error introduced by the numerical stress field approximation. In addition, the results show that the crack orienta- 

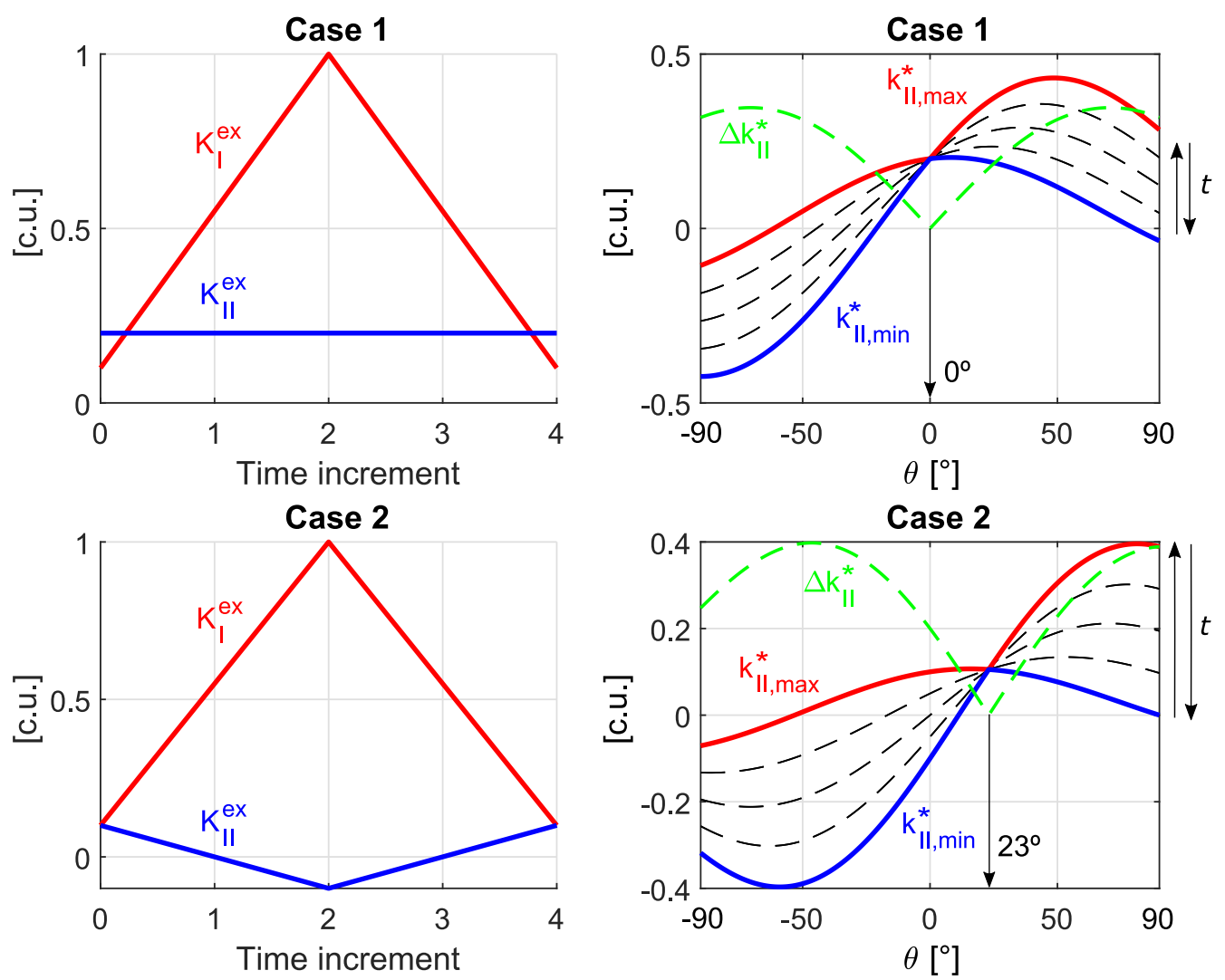

Figure 3: Loading cycle in terms of exact SIFs and application of the $\min \left(\Delta k_{\mathrm{II}}^{*}\right)$ criterion for loading cases 1 and 2 for the Westergaard's problem of reference (solved using the analytical expressions in [13]).

tion predicted by $\min (\Delta \tau)$ criterion is similar to the angles predicted by the maximum $\Delta \sigma_{\mathrm{n}}$ criterion.

\section{Orientation criteria for crack propagation in fretting fatigue}

Forsyth [28] distinguished two stages in the development of cracks: stage I for the nucleation process and stage II for the propagation process. During stage I, two main types of cracks can be observed: type 1, dominated by the range of shear stress $\Delta \tau$ and growing along a direction from $15^{\circ}$ to $35^{\circ}$ with respect to the surface [29] and type 2, dominated by the normal stress 
a) Case 1

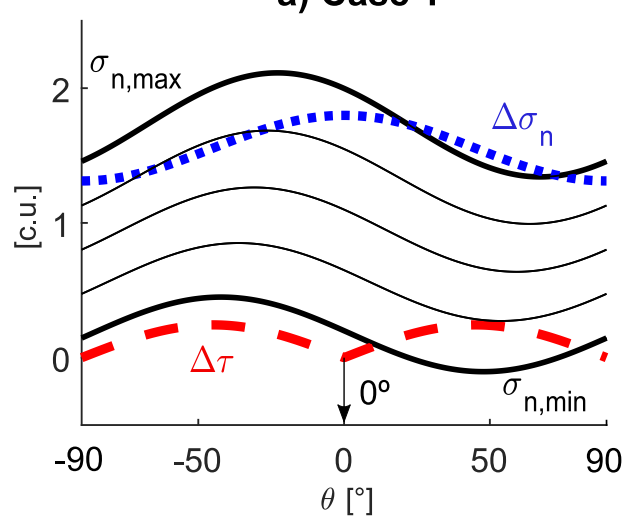

c) Case 2

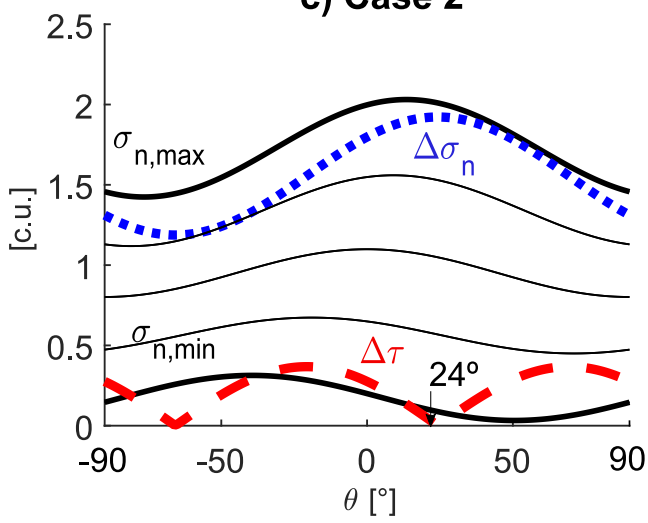

b) Case 1

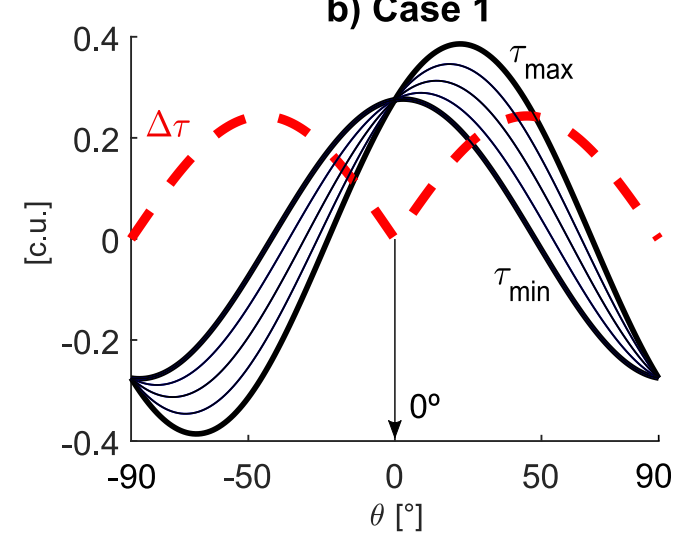

d) Case 2

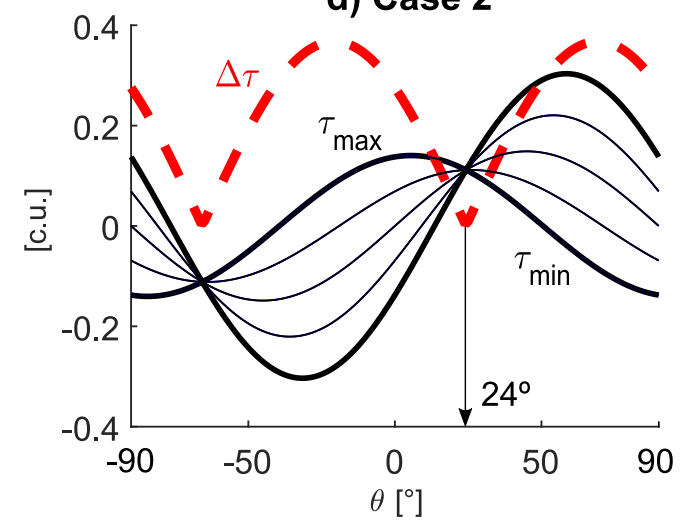

Figure 4: Application of the $\min (\Delta \tau)$ criterion for loading cases 1 and $2\left[{ }^{*}\right]$.

range $\Delta \sigma_{\mathrm{n}}$ and growing along a direction from $75^{\circ}$ to $90^{\circ}$ [19]. Critical plane approaches applied in conjunction with average methods have been a satisfactory tool for the prediction of the initial crack orientation [30, 31]. During stage II, the crack is subjected to a non-proportional mixed mode loading. In this way, a crack kinks along a direction of approximately $70^{\circ}$ to $60^{\circ}$ to the surface $[19,32]$. This direction is where $\Delta \tau$ or the mode II stress intensity range is minimum as pointed out by Dubourg and Lamacq [19] and Faanes [29], respectively. As the crack grows and in the presence of an oscillatory bulk load, the crack deflects into a direction perpendicular 
to the bulk load axis because the stress state becomes uniaxial in practice sufficiently far from the contact zone. However, a crack will probably arrest without deflecting in the absence of an oscillatory bulk load such as in plain fretting tests [32]. In other cases, the crack orientation can be highly influenced by the material microstructure when the crack is close to the crack arrest length or during the crack nucleation in plain fretting tests $[23,33,34]$.

In the literature, several crack orientation criteria have been successfully employed for stage II. Dubourg and Lamacq [19] obtained a good agreement using the $\max \left(\Delta \sigma_{\mathrm{n}, \text { eff }}\right)$ and $\max \left(\Delta k_{\mathrm{I}}^{*}\right)$ in cylindrical-to-flat type contact. Noraphaiphipaksa et al. studied in [35] the fretting fatigue crack paths with cylindrical-on-flat contact using the criterion of maximum range of circumferential stresses (taking into account negative circumferential stresses), obtaining a good agreement with the experimental results. In addition, the predicted crack paths with $\max \left(\Delta k_{\mathrm{I}}^{*}\right)$ and $\max (\mathrm{d} a / \mathrm{d} N)$ obtained by Baietto et al. [21] were also in agreement with the experimental results for a cylindrical-to-flat type contact. Pereira and Wahab [17] obtained good estimations of the experimental results when applying $\max \left(\Delta k_{\mathrm{I}}^{*}\right)$ to a fretting fatigue problem with cylinder-to-plane contact. More recently, Vázquez et al. [36] applied the Smith-Watson-Topper criterion and $\max \left(\Delta k_{\mathrm{I}}^{*}\right)$ for crack propagation during stage II in an incomplete contact configuration, obtaining satisfactory results. Lastly, Llavori et al. [34] compared the predictions of the criterion of $\min (\Delta \tau)$ and $\max \left(\Delta \sigma_{\mathrm{n}, \text { eff }}\right)$ in a plain fretting problem under incomplete contact configuration, obtaining a lower deviation of the predictions during the first stages of the propagation with the $\min (\Delta \tau)$ criterion. However, $\max \left(\Delta \sigma_{\mathrm{n} \text {,eff }}\right)$ criterion was able to better capture the crack 
path during the last stage of crack propagation although presenting an unrealistic erratic zigzag behaviour. Despite these several crack propagation analyses can be found in the literature under fretting conditions, there is still not consensus on which criterion gives the best predictions. Furthermore, another open question is whether it is necessary to take into account negative circumferential stress and the corresponding virtual mode I stress intensity factor.

On the other hand, in flat-to-flat contacts, the predicted crack paths with $\min (\Delta \tau)$ obtained by Giner et al. [16] correlate very well with the experimental observations. Other authors have reported that the criterion is in good agreement with the crack paths obtained with a complete contact configuration [37, 38]. Furthermore in [14], Navarro et al. analysed the nucleation and early crack paths in fretting fatigue with incomplete contact using critical plane analysis and fracture mechanics approaches. The results showed that the criterion of minimum $\Delta K_{\text {II }}$ gives a good agreement with the experimental crack trajectories. However, Cardoso et al. [20] obtained a poor agreement with the experimental results when applying $\min (\Delta \tau)$ to a cylindrical-to-flat contact type. We show in this work that the $\min (\Delta \tau)$ criterion leads to good results even for this type of contact.

\section{Experimental results obtained from literature}

A brief summary of the experimental results and tests employed to evaluate the applicability of the criterion is presented in this section. The works have been selected in order to include several different test configurations under incomplete contact. Three different test types are numerically assessed: plain fretting test, plain fretting test on pre-stressed specimen and 
single clamp fretting fatigue test.

\subsection{Test 1: Plain fretting test with a cylinder on flat contact}

First, the experimental data reported by Proudhon et al. [23] regarding a plain fretting test with cylinder on flat contact under partial slip regime is assessed in this work. The materials of the specimen and indenter are 2024-T351 and 7075-T6, respectively. The radius of the cylinder is $49 \mathrm{~mm}$. A constant normal force of $320 \mathrm{~N} / \mathrm{mm}$ and an alternating tangential force of $240 \mathrm{~N} / \mathrm{mm}$ per unit thickness are applied to the indenter with a stress ratio of -1 . The coefficient of friction (COF) was measured by the authors under partial slip conditions in a previous work resulting in a value of 1.1 [39]. Fig. 5 shows the experimental crack path reported in [23]. In this case, the crack is characterised using synchrotron X-ray micro-tomography. It can be observed that multiple cracks nucleate at the edge of the contact (stage I). Then, the crack direction changes to $30^{\circ}$ with respect to the surface normal once the crack length is about 30-50 microns. The authors pointed out that the scatter of the inclination angle during initiation is much higher than in the propagation stage. On the other hand, cracks usually arrest in plain fretting tests when they escape from the high stress gradient produced by the contact. Therefore, scattering during propagation will increase as the crack is close to the arrest length because of the reduction in the energy available for crack growth.

\subsection{Test 2: Plain fretting test on pre-stressed specimen with a cylinder on flat contact}

The experimental data regarding plain fretting tests on a pre-stressed specimen with a cylinder on flat contact configuration under partial slip 


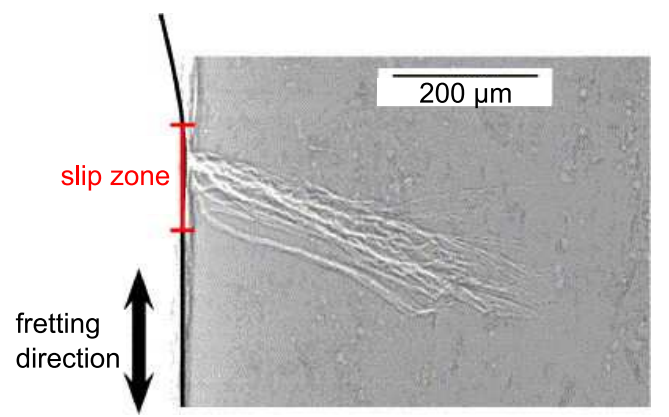

Figure 5: Experimental crack paths after $500 \times 10^{3}$ cycles obtained by Proudhon et al. [23] (reproduced with permission of Elsevier).

regime published by Baietto et al. [21] is presented in this subsection. These experiments were used as reference in [20]. The materials of the plane specimen and cylindrical indenter are a steel alloy 35NCD16 and a heat treated steel 100C6, respectively. The radius of the cylinder is $80 \mathrm{~mm}$ and the thickness is $8 \mathrm{~mm}$. A plane strain condition is assumed. The yield stress is not exceeded at any point of the specimen [21]. A constant normal force $(P)$ of $1000 \mathrm{~N} / \mathrm{mm}$ and an alternating tangential force $(Q)$ of 500 $\mathrm{N} / \mathrm{mm}$ are applied to the cylinder. The COF is assumed to be 0.9 [21], ensuring partial slip conditions. The COF was measured in [21] applying a variable displacement method and assuming the COF as the stabilized COF at the transition between partial and gross slip conditions [39]. In addition, a static uniaxial load $\left(\sigma_{\mathrm{s}}\right)$ is applied to the plane specimen with different magnitudes $(0,70,140,210,280 \mathrm{MPa})$. Tests were interrupted at different stages and plane samples were cut through the cross section in order to examine the crack paths. Fig. 6 shows the experimental crack path obtained with $\sigma_{\text {static }}=70$ and $180 \mathrm{MPa}$. It can be observed that two cracks grow symmetrically oriented beneath the indenter at both contact edges. 

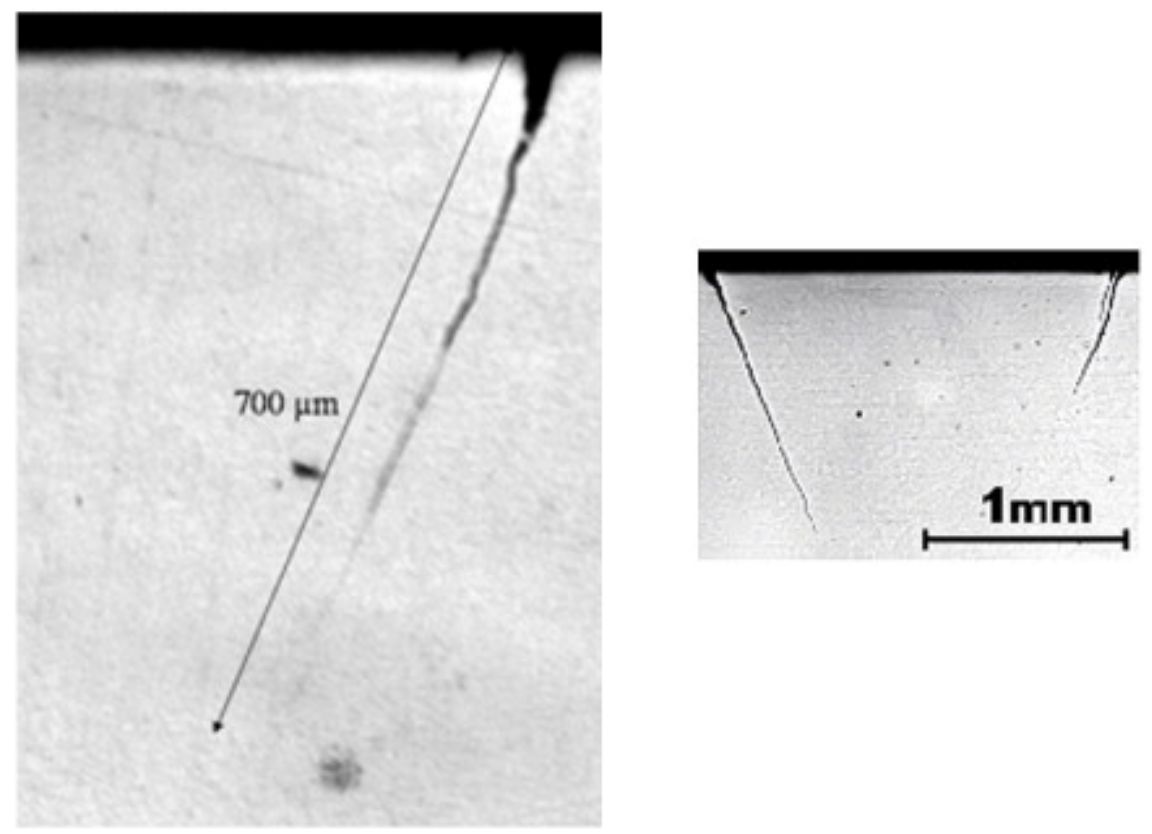

Figure 6: Crack path at the cross section of the specimen with $\sigma_{s}=70 \mathrm{MPa}$ (left) and $\sigma_{s}=180 \mathrm{MPa}$ (right), results from [21] (reproduced with permission of Elsevier).

\subsection{Test 3: Single clamp fretting fatigue test with a cylinder on flat contact}

Another experimental test analysed in this work is the fretting fatigue test with a cylinder-to-flat contact type carried out by Hojjati-Talemi et al. [22]. The crack path was recently assessed in [17], obtaining a good agreement with the $\max \left(\Delta k_{\mathrm{I}}\right)$ criterion. However, it has to be said that during the calculation of $\Delta k_{\mathrm{I}}$ in [17], negative $k_{\mathrm{I}}$ values were considered. Since crack face contact avoids interpenetration, negative mode I stress intensity factors are unrealistic. Instead, the use of $\min \left(\Delta k_{\mathrm{II}}^{*}\right)$ has a more physical meaning, being the criterion which governs the crack path trajectories under fretting fatigue as shown in this work. The material of the dog bone specimen and the cylindrical indenter is aluminium 2024-T3. The radius of the cylinder is $50 \mathrm{~mm}$ and the thickness of indenter and specimen is 4 
mm. A constant normal force per unit thickness of $135.7 \mathrm{~N} / \mathrm{mm}$ is applied to the indenter and an alternating axial stress of $100 \mathrm{MPa}$ is applied to the dog bone specimen with a stress ratio of 0.1 . The rig where the indenter is assembled is rigidly fixed allowing the generation of a tangential force between specimen and indenter. The maximum tangential force measured during the test was $38.8 \mathrm{~N} / \mathrm{mm}$ corresponding to the maximum value of axial stress. The ratio of the tangential force is -1 and it is in-phase with the cyclic axial stress. The COF is measured by the authors under partial slip conditions resulting in a value of 0.65 . Fig. 7 shows the experimental crack path obtained under the conditions explained above. In this case, the crack initiation is located at the right hand side of the contact edge, where the $\sigma_{\text {axial }}$ is applied.

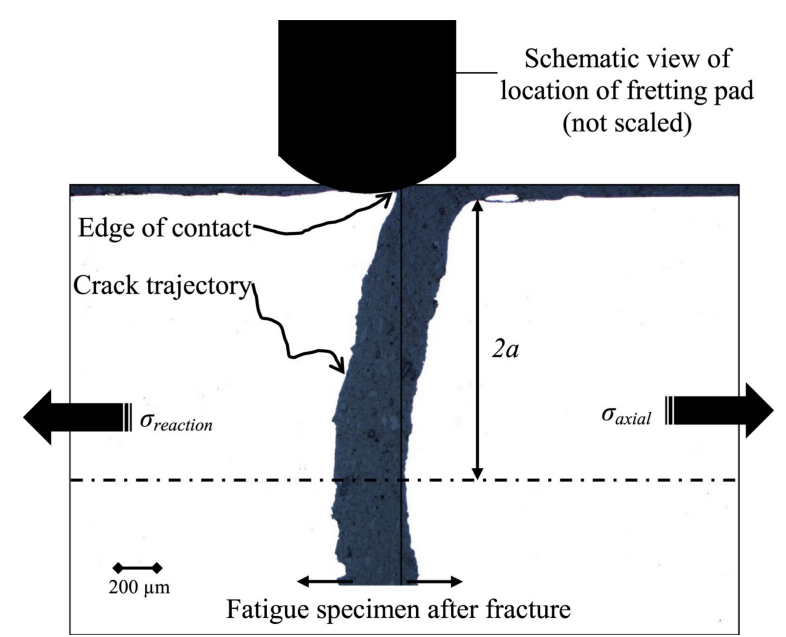

Figure 7: Experimental crack path after complete fracture, results from [22] (reproduced with permission of Elsevier). 


\section{Numerical modelling of crack propagation}

In this work, an Abaqus implementation of the extended finite element method [27] is employed to model crack propagation. Thus, the crack is included in the numerical model without the need of remeshing. Further details can be found in [16] and [27]. In fretting fatigue, crack closure is likely to happen even for positive loading stress ratios due to the contact pressure. Therefore, the numerical model must capture the crack closure and friction between the crack faces $(\mathrm{CF})$. Hence, the X-FEM implementation incorporates crack face contact with friction as reported in [18, 40]. The friction model between the indenter and specimen is a Coulomb model with a Lagrange multiplier contact formulation. The Young's modulus $(E)$, Poisson's ratio $(\nu)$ and COF between CF used for each test are presented in Table 1.

Table 1: Elastic material properties of the numerical models.

\begin{tabular}{cccc}
\hline Material & $E(\mathrm{GPa})$ & $\nu(-)$ & COF between CF(-) \\
\hline 2024-T351 (Specimen test 1) & 72 & 0.3 & 0.8 \\
7075-T6 (Indenter test 1) & 72.4 & 0.33 & - \\
35NCD16 (Indenter test 2) & 200 & 0.3 & - \\
100C6 (Specimen test 2) & 195 & 0.3 & 0.3 \\
2024-T3 (Indenter and specimen test 3) & 72.1 & 0.33 & 0.8
\end{tabular}

An initial inclined crack $\left(a_{0}\right)$ with the inclination reported in the experimental works has been assumed as the initial crack for each model. An initial size of 50 microns has been defined for all the numerical models, being at least 2-3 times the material grain size in all cases. For each crack growth increment, X-FEM is used to obtain the linear-elastic stress field ahead the crack tip. As explained in Section 2, the stress field is evaluated to obtain the crack propagation angle and, successively, the crack is propagated using 
a crack increment size of 50 microns.

A 2D finite element model has been considered to represent the fretting fatigue tests. Boundary conditions and applied loads are shown in Fig. 8 ( $t \mathrm{t}$ represents the reported total thickness in each case). Due to symmetry conditions, only half of the test has been modelled for test 2 and 3 . In addition, multipoint constraints (MPC) have been employed in the nodes located on the top edge of the indenter in order to avoid the rotation of the indenter. The element size in the region of interest and near the contact of indenter and specimen is 10 microns. The ratios between the contact semi-width and the element size for test 1, 2 and 3 are 70, 97 and 47, respectively. Plane strain quadrilateral elements with full integration have been used. For Test 1, only a normal constant load and alternating tangential force are applied to the indenter. For Test 2, a static load of two different magnitudes has been applied together with an alternating tangential force and a constant normal force. The stress field is analysed from step 2 to 5. For Test 3, a normal constant load has been applied combined with an alternating axial and reaction stress. The reaction stress is calculated as proposed in [22]. In this case, the stress field is analysed from step 2 to 6 . A summary of the loading history applied to each test is shown in Fig. 8 (right).

\section{Numerical results}

As the objective of this work is to show the suitability of the minimum shear stress range criterion for the prediction of fretting fatigue crack paths with incomplete contact configurations, results will be focused on the predicted crack paths and angles with the $\min (\Delta \tau)$ criterion. The predicted 

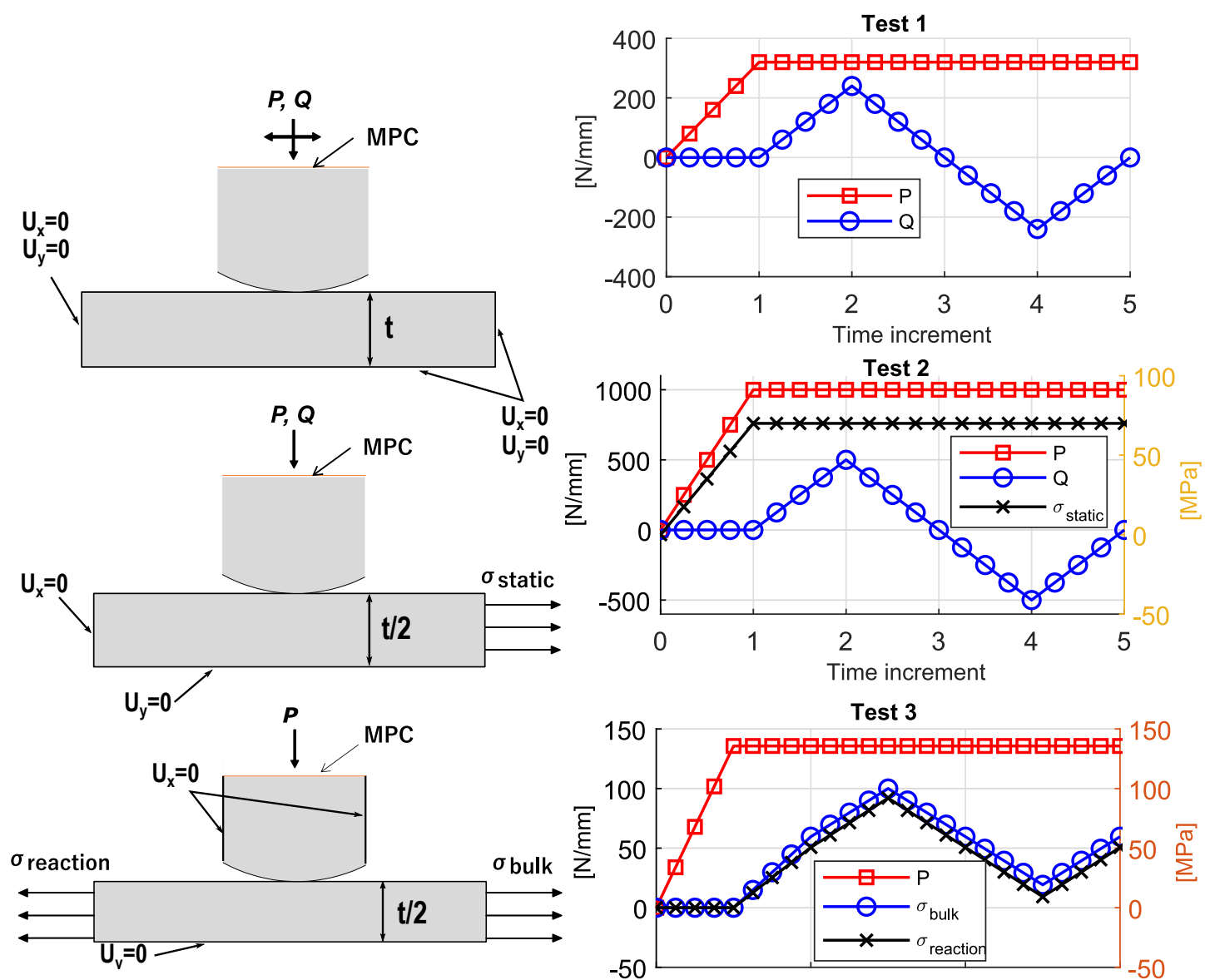

Test 3

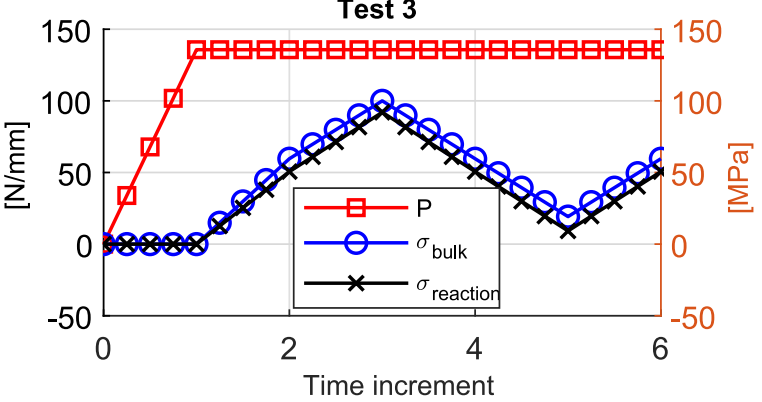

Figure 8: From top to bottom: sketch of the boundary conditions (left) and loads (right) for the three tests: numerical model of plain fretting, plain fretting on pre-stressed specimen and fretting fatigue. 
crack paths are compared with the experimental crack paths and a brief discussion of the differences found is also presented. In addition, a finite element model without crack, but with a more refined mesh (5 microns), has been developed for each case to calculate the semi-contact width $\left(a^{*}\right)$, normal pressure $\left(p_{0}\right)$, semi-slip width $\left(c^{*}\right)$, eccentricity of the stick zone $\left(e^{*}\right)$ and maximum axial stress at the contact trailing edge $\sigma_{x x}^{\max }$ for a better understanding of the fretting conditions under partial slip regime. Results of the uncracked model is shown in Table 2.

Table 2: Relevant parameters affecting fretting conditions for each test.

\begin{tabular}{cccccc}
\hline Test & $a^{*}(\mathrm{~mm})$ & $p_{0}(\mathrm{MPa})$ & $c^{*}(\mathrm{~mm})$ & $\sigma_{x x}^{\max }(\mathrm{MPa})$ & $e^{*}(\mathrm{~mm})$ \\
\hline 1 & 0.705 & 289.3 & 0.400 & 467.20 & - \\
$2\left(\sigma_{\text {static }}=70 \mathrm{MPa}\right)$ & 0.967 & 658.40 & 0.642 & 1017.25 & 0.034 \\
$2\left(\sigma_{\text {static }}=180 \mathrm{MPa}\right)$ & 0.967 & 658.40 & 0.642 & 1049.18 & 0.068 \\
3 & 0.470 & 187.30 & 0.345 & 254.40 & 0.095
\end{tabular}

\subsection{Test 1: Plain fretting test with a cylinder on flat contact}

Tests performed by Proudhon et al. [23] resulted in crack arrest due to the absence of a fatigue axial load. Short cracks of around $0.4 \mathrm{~mm}$ were observed in the specimens after $500 \times 10^{3}$ cycles as shown in Fig. 5. Despite the cracks are not very long, a crack propagation phase (stage II) was clearly observed after the crack kink from the initial crack developed during the nucleation phase (about 40-50 microns). Experimental crack paths are scaled and shown on the background together with the numerically predicted crack. As mentioned previously, the scatter found in the experimental crack paths can be caused by the material microstructure that is not taken into account in LEFM. However, Fig. 9 shows a good agreement between the experimental and the predicted crack trajectories. 
The predicted crack inclination obtained with the minimum shear stress range criterion varies from $18^{\circ}$ to $31^{\circ}$. The experimental orientation of the crack at a distance of 200 microns reported by Proudhon et al. [23] varied from $5^{\circ}$ to $29^{\circ}$, although the main developed straight crack was inclined from $25^{\circ}$ to $28^{\circ}$ to the normal of the surface. The employment of X-ray micro-tomography evidences the scatter of the crack orientation under plain fretting conditions [23]. The experimental results show a significant scattering of the propagation plane orientation in the absence of an applied axial load (cyclic or static), because the orientation can be more influenced by the grain boundaries due to the relative small energy available at the crack tip of a crack that has already escaped from the influence of the normal and tangential load. This result explains why in some cases the predicted crack orientation does not match with the experimental results when simplifying a 3D crack trajectory to a 2D planar crack. However, it is experimentally observed that the main crack plane propagation direction is always inclined and pointing beneath the contact region with an angle close between $25^{\circ}$ to $28^{\circ}$ with respect to the normal surface. In conclusion, the 2D planar crack assumption can be employed to predict the main crack orientation, but the comparison with the experimental crack orientation needs to be carefully performed, ensuring the measurement of the average inclination of the main developed crack and not solely in one of the through thickness plane crack orientations. 


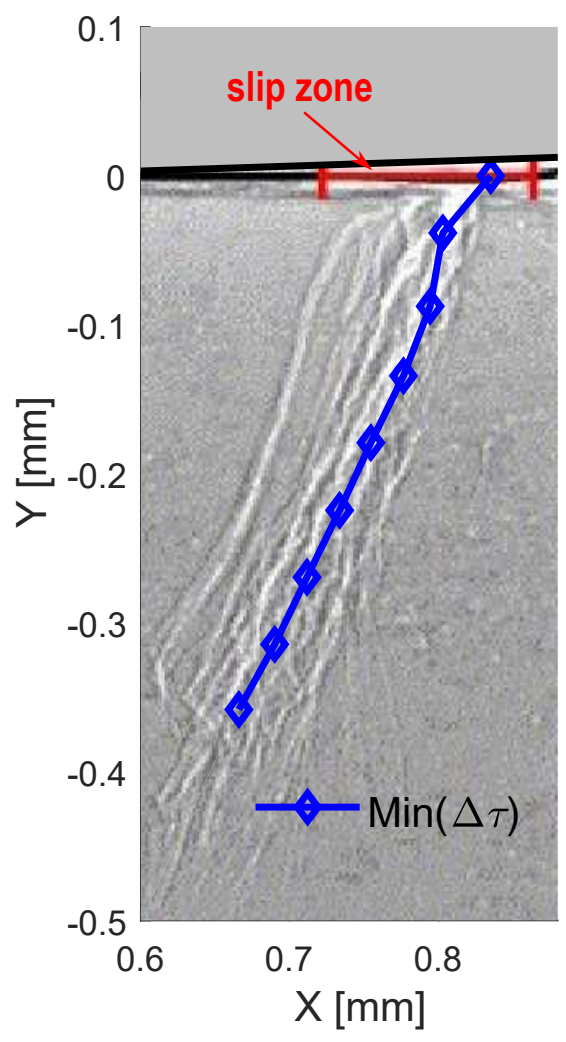

Figure 9: Predicted propagation path using X-FEM and $\min (\Delta \tau)$ vs. experimental results by Proudhon et al. [23] (Test 1).

6.2. Test 2: Plain fretting test on pre-stressed specimen with a cylinder on flat contact

Although there is no cyclic axial bulk stress in these experiments, the applied static load allows to obtain longer crack paths compared to plain fretting tests. The two crack paths reported by Baietto et al. in Fig. 6 with $\sigma_{\text {static }}$ equal to 70 and $180 \mathrm{MPa}$ have been numerically assessed.

Since the unique difference between both tests is the applied static load, the stress ranges are almost constant along the prospective angles and the only difference is the mean stress. Therefore, cracks predicted by the $\min (\Delta \tau)$ criterion are very similar for both tests. Finally, we find a very 
good agreement with the experimental results of Baietto et al. [21] and the prediction through the $\min (\Delta \tau)$ criterion, as shown in Fig. 10. Note that Cardoso et al. [20] predicted the crack to grow pointing outside of the contact area using the $\min (\Delta \tau)$ criterion, contrary to the experimental observation. However, we have obtained that the criterion is able to capture the crack propagation. Differences may arise in the methodology employed to look for the prospective minimum shear stress range direction employed by Cardoso et al. [20] and the bad estimation employed for the initial crack.

\subsection{Test 3: Single clamp fretting fatigue test with a cylinder on flat contact}

The experiment carried out by Hojjati-Talemi et al. [22] that finished in the complete fracture of the specimen as shown in Fig. 7 has been also numerically assessed. As shown in Fig. 11, a good agreement is observed between the experimental results of Hojjati-Talemi et al. [22] and the numerical prediction through the $\min (\Delta \tau)$ criterion. Differences between experimental and predicted crack paths may arise from the influence of local effects such as the microstructure. Nevertheless, inclination and direction of both cracks are very similar. In addition, it can be observed that the predicted inclination with respect to the normal surface is decreasing as the crack grows. At a distance of $2 a$, the predicted crack direction is very close to the normal surface direction because, as expected, the crack orientation is being mainly dominated by the cyclic bulk load.

\section{Conclusions}

In this work, a numerical methodology has been proposed to assess the crack orientation propagation stage with the minimum shear stress range 

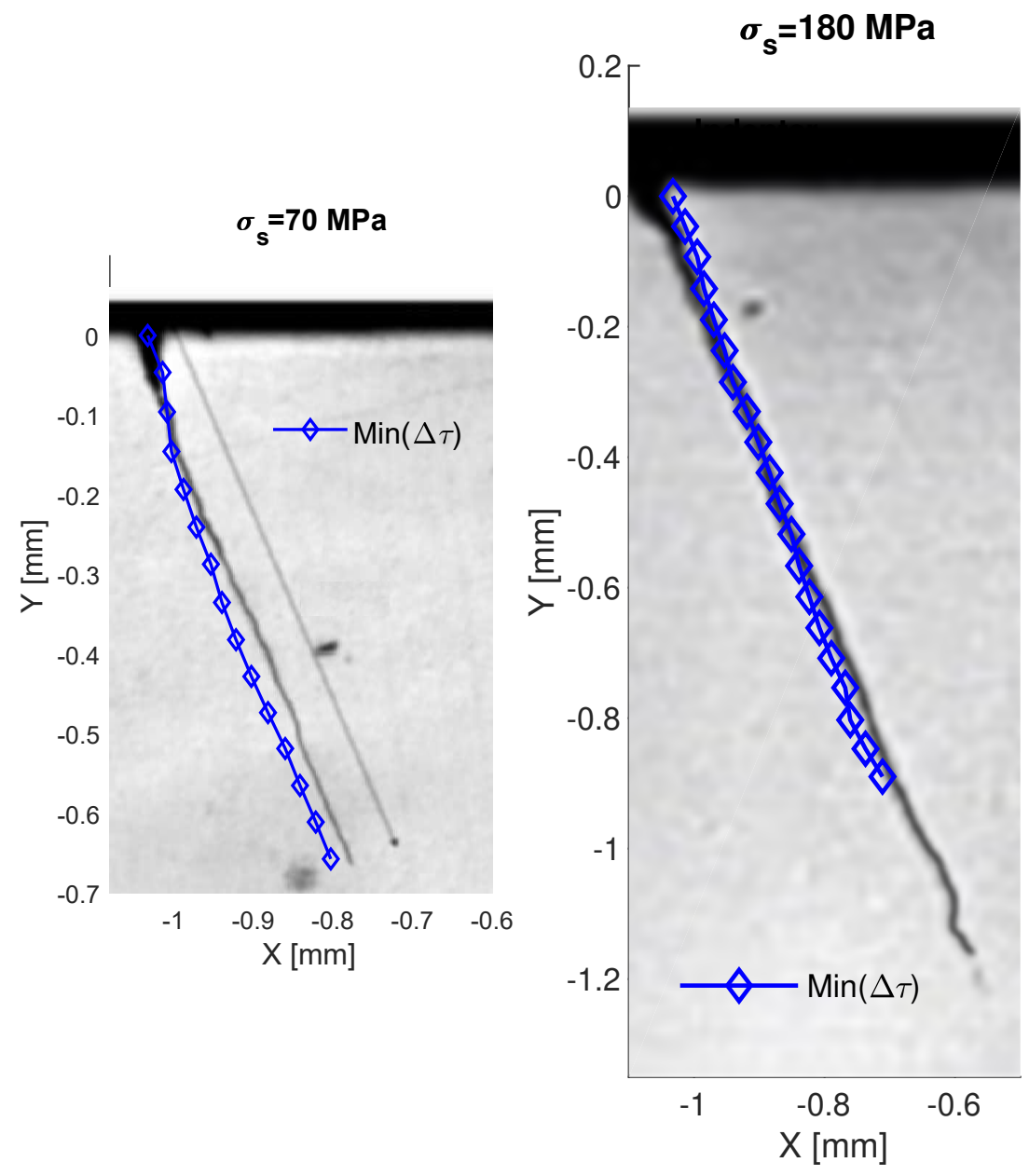

Figure 10: Predicted propagation path using $\mathrm{X}-\mathrm{FEM}$ and $\min (\Delta \tau)$ vs. experimental results by Baietto et al. [21] (Test 2).

under fretting conditions. Three different tests reported in the literature have been assessed during stage II in fretting fatigue under incomplete contact conditions using the $\min (\Delta \tau)$ crack orientation criterion and X-FEM. The numerical results are in good agreement with the experimental observations, despite some bad estimations reported in the literature. In addition, some indications regarding the implementation of the $\min (\Delta \tau)$ criterion are given. A numerical example based on the well known Westergaard's prob- 


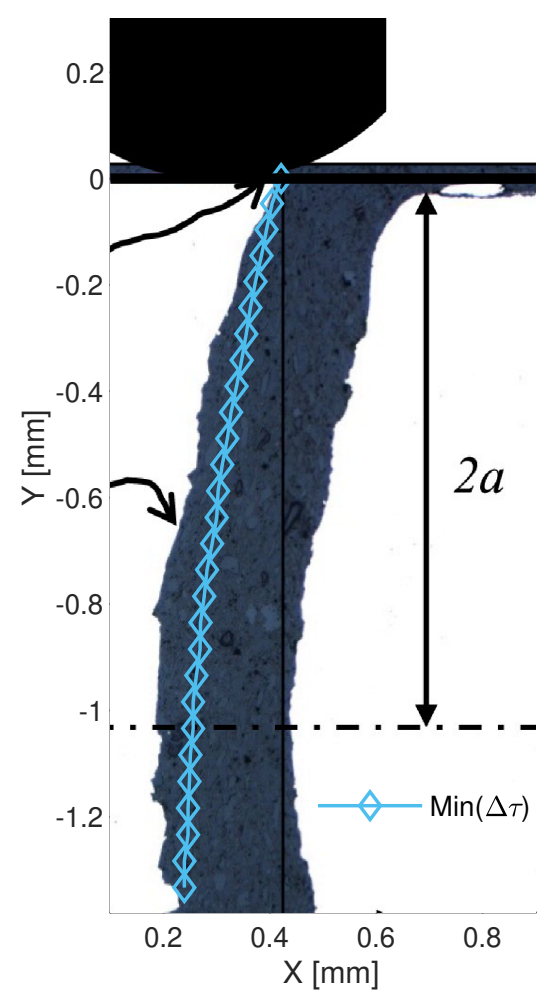

Figure 11: Predicted propagation path using $\mathrm{X}-\mathrm{FEM}$ and $\min (\Delta \tau)$ vs. experimental results by Hojjati-Talemi et al. [22] (Test 3).

lem has also been analysed to validate the method, showing concordance between the angles predicted by the $\min (\Delta \tau)$ criterion and the $\min \left(\Delta k_{\mathrm{II}}\right)$ criterion.

\section{Acknowledgments}

The authors gratefully acknowledge the financial support given by the Spanish Ministry of Economy and Competitiveness and the FEDER program through the project DPI2017-89197-C2-1-R, DPI2017-89197-C2-2-R and DPI2014-56137-C2-2-R and the FPI subprogram associated to the project with the reference BES-2015-072070. The support of the Generalitat Va- 
lenciana, Programme PROMETEO 2016/007, is also acknowledged. The financial support given by the Eusko Jaurlaritza under "Programa de apoyo a la investigación colaborativa en áreas estratégicas" (Project MEDECA: Ref. KK-2017/00053, and MEDECA2: Ref. KK-2018/00013) programs is also acknowledged.

\section{References}

[1] L. Susmel, R. Tovo, and D. F. Socie. Estimating the orientation of Stage I crack paths through the direction of maximum variance of the resolved shear stress. International Journal of Fatigue, 58:94-101, jan 2014. ISSN 01421123. doi: 10.1016/j.jffatigue.2013.05.007. URL https://www.sciencedirect.com/science/ article/pii/S0142112313001497.

[2] I. Varfolomeev, M. Burdack, S. Moroz, D. Siegele, and K. Kadau. Fatigue crack growth rates and paths in two planar specimens under mixed mode loading. International Journal of Fatigue, 58:12-19, jan 2014. ISSN 0142-1123. doi: 10.1016/J.IJFATIGUE.2013.04.013. URL https://www.sciencedirect.com/ science/article/pii/S0142112313001199.

[3] J. Qian and A. Fatemi. Mixed mode fatigue crack growth: A literature survey. Engineering Fracture Mechanics, 55(6):969-990, 1996. ISSN 00137944. doi: 10. 1016/S0013-7944(96)00071-9.

[4] F. Erdogan and G. C. Sih. On the Crack Extension in Plates Under Plane Loading and Transverse Shear. Journal of Basic Engineering, 85(4):519, 1963. ISSN 00219223. doi: 10.1115/1.3656897. URL http://fluidsengineering. asmedigitalcollection . asme .org/article . aspx?articleid=1431534.

[5] G. C. Sih. Strain-energy-density factor applied to mixed mode crack problems. International Journal of Fracture, 10(3):305-321, sep 1974. ISSN 0376-9429. doi: 10.1007/BF00035493. URL http://link. springer.com/10.1007/BF00035493.

[6] K. Palaniswamy and W. G. Knauss. Propagation of a crack under general, in-plane tension. International Journal of Fracture Mechanics, 8(1):114-117, mar 1972. ISSN 
0020-7268. doi: 10.1007/BF00185207. URL http://link.springer.com/10.1007/ BF00185207.

[7] R. Pettit. Crack turning in integrally stiffened aircraft structures. PhD thesis, 2000. URL http://adsabs .harvard.edu/abs/2000PhDT ......126P.

[8] E. Giner, N. Sukumar, F. D. Denia, and F. J. Fuenmayor. Extended finite element method for fretting fatigue crack propagation. International Journal of Solids and Structures, 45(22-23):5675-5687, 2008. ISSN 00207683. doi: 10.1016/j.ijsolstr.2008. 06.009 .

[9] X. Yu, L. Li, and G. Proust. Fatigue crack growth of aluminium alloy 7075T651 under proportional and non-proportional mixed mode I and II loads. Engineering Fracture Mechanics, 174:155-167, apr 2017. ISSN 0013-7944. doi: 10. 1016/J.ENGFRACMECH.2017.01.008. URL https://www.sciencedirect.com/ science/article/pii/S0013794417300310.

[10] R. J. Nuismer. An energy release rate criterion for mixed mode fracture. International Journal of Fracture, 11(2):245-250, apr 1975. ISSN 0376-9429. doi: 10.1007/BF00038891. URL http://link. springer.com/10.1007/BF00038891.

[11] F. Hourlier, H. D'Hondt, M. Truchon, and A. Pineau. Fatigue Crack Path Behavior Under Polymodal Fatigue. In Multiaxial Fatigue, pages 228-228-21. ASTM International, 100 Barr Harbor Drive, PO Box C700, West Conshohocken, PA 194282959, 1985. doi: 10.1520/STP36226S. URL http://www.astm.org/doiLink.cgi? STP36226S.

[12] H. Kitagawa, R. Yuuki, K. Tohgo, and M. Tanabe. $\Delta$ K-Dependency of Fatigue Growth of Single and Mixed Mode Cracks Under Biaxial Stress. In Multiaxial Fatigue, pages 164-164-20. ASTM International, 100 Barr Harbor Drive, PO Box C700, West Conshohocken, PA 19428-2959, 1985. doi: 10.1520/STP36223S. URL http://www . astm.org/doiLink.cgi?STP36223S.

[13] D. Infante-García, G. Quian, H. Miguélez, and E. Giner. Analysis of the effect of out-of-phase biaxial fatigue loads on crack paths in cruciform specimens using XFEM. International Journal of Fatigue, 123:87-95, jun 2019. ISSN 01421123. doi: 10.1016/j.ijfatigue.2019.01.019. URL https://linkinghub.elsevier.com/ retrieve/pii/S0142112318307321. 
[14] C. Navarro, J. Vázquez, and J. Domínguez. Nucleation and early crack path in fretting fatigue. International Journal of Fatigue, 100: 602-610, jul 2017. ISSN 0142-1123. doi: 10.1016/J.IJFATIGUE. 2016.12.028. URL https://www.sciencedirect.com/science/article/pii/ S0142112316304376?via\{\\%\}3Dihub.

[15] C. Qian, M. Wang, B. Wu, S. Dai, and J. C. M. Li. Mixed-Mode Fatigue Crack Growth in Stainless Steels Under Biaxial Loading. Journal of Engineering Materials and Technology, 118(3):349, jul 1996. ISSN 00944289. doi: 10.1115/ 1.2806817. URL http://materialstechnology.asmedigitalcollection.asme. org/article. aspx?articleid=1425465.

[16] E. Giner, M. Sabsabi, J. Ródenas, and F. J. Fuenmayor. Direction of crack propagation in a complete contact fretting-fatigue problem. International Journal of Fatigue, 58:172-180, jan 2014. ISSN 0142-1123. doi: 10.1016/J.IJFATIGUE. 2013.03.001. URL https://www.sciencedirect.com/science/article/pii/ S0142112313000741\{\\\}b0060.

[17] K. Pereira and M. Abdel Wahab. Fretting fatigue crack propagation lifetime prediction in cylindrical contact using an extended MTS criterion for non-proportional loading. Tribology International, 115:525-534, nov 2017. ISSN 0301-679X. doi: 10.1016/J.TRIBOINT.2017.06.026. URL https://www.sciencedirect.com/ science/article/pii/S0301679X17303146.

[18] E. Giner, M. Sabsabi, and F.J. Fuenmayor. Calculation of $K_{I I}$ in crack face contacts using X-FEM. Application to fretting fatigue. Engineering Fracture Mechanics, 78(2):428-445, jan 2011. ISSN 0013-7944. doi: 10.1016/J.ENGFRACMECH. 2010.11.002. URL https://www.sciencedirect.com/science/article/pii/ S0013794410004650.

[19] M. C. Dubourg and V. Lamacq. Stage II Crack Propagation Direction Determination Under Fretting Fatigue Loading: a New Approach in Accordance with Experimental Observations. In Fretting Fatigue: Current Technology and Practices, pages 436-436-15. ASTM International, 100 Barr Harbor Drive, PO Box C700, West Conshohocken, PA 19428-2959, 2000. doi: 10.1520/STP14746S. URL http://www.astm.org/doiLink. cgi?STP14746S. 
[20] R.A. Cardoso, J.A. Araújo, J.L.A. Ferreira, and F.C. Castro. Crack path simulation for cylindrical contact under fretting conditions. Frattura ed Integrità Strutturale, 10(35):405-413, 2016. ISSN 1971-8993. doi: 10.3221/igf-esis.35.46. URL https: //www.fracturae.com/index.php/fis/article/view/IGF-ESIS.35.46.

[21] M.C. Baietto, E. Pierres, A. Gravouil, B. Berthel, S. Fouvry, and B. Trolle. Fretting fatigue crack growth simulation based on a combined experimental and XFEM strategy. International Journal of Fatigue, 47:31-43, feb 2013. ISSN 0142-1123. doi: 10.1016/J.IJFATIGUE.2012.07.007. URL https://www. sciencedirect.com/ science/article/pii/S0142112312002344.

[22] R. Hojjati-Talemi, M. Abdel Wahab, J. De Pauw, and P. De Baets. Prediction of fretting fatigue crack initiation and propagation lifetime for cylindrical contact configuration. Tribology International, 76:73-91, 2014. ISSN 0301679X. doi: 10.1016/j.triboint.2014.02.017. URL http://dx.doi.org/10.1016/j.triboint. 2014.02 .017 .

[23] H. Proudhon, J. Y. Buffière, and S. Fouvry. Characterisation of fretting fatigue damage using synchrotron X-ray micro-tomography. Tribology International, 39 (10):1106-1113, 2006. ISSN 0301679X. doi: 10.1016/j.triboint.2006.02.047.

[24] B. Cotterell and J.R. Rice. Slightly curved or kinked cracks. International Journal of Fracture, 16(2):155-169, apr 1980. ISSN 0376-9429. doi: 10.1007/BF00012619. URL http://link.springer.com/10.1007/BF00012619.

[25] T. L. Anderson. Fracture Mechanics. CRC Press, mar 2017. ISBN 9781315370293. doi: 10.1201/9781315370293. URL https://www.taylorfrancis.com/books/ 9781315370293.

[26] E. Giner, F. J. Fuenmayor, L. Baeza, and J. E. Tarancón. Error estimation for the finite element evaluation of GI and GII in mixed-mode linear elastic fracture mechanics. Finite Elements in Analysis and Design, 41(11-12):1079-1104, 2005. ISSN 0168874X. doi: 10.1016/j.finel.2004.11.004.

[27] E. Giner, N. Sukumar, J. E. Tarancón, and F. J. Fuenmayor. An Abaqus implementation of the extended finite element method. Engineering Fracture Mechanics, 76(3):347-368, 2009. ISSN 00137944. doi: 10.1016/j.engfracmech.2008.10.015. URL http://dx.doi.org/10.1016/j.engfracmech.2008.10.015. 
[28] P. J. E. Forsyth. A two-stage process of fatigue crack growth. In: Proc crack propagation symposium, the College of Aeronautics, 1:76-94, 1961.

[29] S. Faanes. Inclined cracks in fretting fatigue. Engineering Fracture Mechanics, 52 (1):71-82, sep 1995. ISSN 0013-7944. doi: 10.1016/0013-7944(94)00331-B. URL https://www.sciencedirect.com/science/article/pii/001379449400331B.

[30] J. A. Araújo and D. Nowell. The effect of rapidly varying contact stress fields on fretting fatigue. International Journal of Fatigue, 24(7):763-775, jul 2002. ISSN 01421123. doi: 10.1016/S0142-1123(01)00191-8. URL https://www. sciencedirect. com/science/article/pii/S0142112301001918.

[31] S. Vantadori, G. M. J. Almeida, G. Fortese, G. Pessoa, and J. A. Araújo. Early fretting crack orientation by using the critical plane approach. International Journal of Fatigue, 114:282-288, sep 2018. ISSN 0142-1123. doi: 10.1016/ J.IJFATIGUE.2018.04.015. URL https://www.sciencedirect.com/science/ article/pii/S0142112318301452.

[32] S. Fouvry, D. Nowell, K. Kubiak, and D.A. Hills. Prediction of fretting crack propagation based on a short crack methodology. Engineering Fracture Mechanics, 75(6):1605-1622, apr 2008. ISSN 0013-7944. doi: 10.1016/J.ENGFRACMECH. 2007.06.011. URL https://www.sciencedirect.com/science/article/pii/ S0013794407002792.

[33] A. De Pannemaecker, S. Fouvry, and J. Buffiere. Introduction of a reverse simulation approach to identify the fatigue stress intensity factor crack arrest threshold from fretting cracking experiments. Tribology International, 76:122-132, 2014. ISSN 0301679X. doi: 10.1016/j.triboint.2013.10.016.

[34] I. Llavori, E. Giner, A. Zabala, D. Infante-Garcia, A. Aginagalde, N. RodríguezFlórez, and X. Gómez. Critical analysis of the suitability of crack propagation direction criteria for 2D cylindrical plain fretting contact. Engineering Fracture Mechanics, apr 2019. ISSN 0013-7944. doi: 10.1016/J.ENGFRACMECH. 2019.04.035. URL https://www.sciencedirect.com/science/article/pii/ S0013794418311731?via\{\\%\}3Dihub.

[35] N. Noraphaiphipaksa, A. Manonukul, and C. Kanchanomai. Fretting Fatigue with Cylindrical-On-Flat Contact: Crack Nucleation, Crack Path and Fatigue Life. $M a-$ 
terials, 10(2):155, feb 2017. ISSN 1996-1944. doi: 10.3390/ma10020155. URL http://www.mdpi.com/1996-1944/10/2/155.

[36] J. Vázquez, A. Carpinteri, L. Bohórquez, and S. Vantadori. Fretting fatigue investigation on Al 7075-T651 alloy: Experimental, analytical and numerical analysis. Tribology International, mar 2019. ISSN 0301-679X. doi: 10.1016/J.TRIBOINT. 2019.03.028. URL https://www.sciencedirect.com/science/article/pii/ S0301679X19301483.

[37] K. Pereira and M. Abdel Wahab. Minimum shear stress range: a criterion for crack path determination. Journal of Physics: Conference Series, 843(1):012053, may 2017. ISSN 1742-6588. doi: 10.1088/1742-6596/843/ 1/012053. URL http://stacks.iop.org/1742-6596/843/i=1/a=012053?key= crossref.7e5e500783722a949050c697902ba20e.

[38] J. C. Martínez, Libardo V. Vanegas Useche, and M. A. Wahab. Numerical prediction of fretting fatigue crack trajectory in a railway axle using XFEM. International Journal of Fatigue, 100:32-49, jul 2017. ISSN 0142-1123. doi: 10.1016/ J.IJFATIGUE.2017.03.009. URL https://www.sciencedirect.com/science/ article/pii/S0142112317300968?via\{\\%3Dihub.

[39] H. Proudhon, S. Fouvry, and J.-Y. Buffière. A fretting crack initiation prediction taking into account the surface roughness and the crack nucleation process volume. International Journal of Fatigue, 27(5):569-579, may 2005. ISSN 0142-1123. doi: 10.1016/J.IJFATIGUE.2004.09.001. URL https ://www.sciencedirect.com/ science/article/pii/S0142112304001938.

[40] E. Giner, M. Tur, J. E. Tarancón, and F. J. Fuenmayor. Crack face contact in X-FEM using a segment-to-segment approach. International Journal for Numerical Methods in Engineering, 82(11):n/a-n/a, 2009. ISSN 00295981. doi: 10.1002/nme. 2813. URL http://doi.wiley.com/10.1002/nme.2813. 